\title{
ESTUDO DOS COMPOSTOS PRÉ-COMBUSTÍVEIS OBTIDOS A PARTIR DA PIRÓLISE TÉRMICA DO LODO DE ESGOTO ANAERÓBIO COLETADO NA ETE-MANGUEIRA EM PERÍODO CHUVOSO E DE ESTIAGEM
}

\author{
S. T. S. VERAS ${ }^{1}$, I. A. T. A. RIBEIRO ${ }^{2}$, J. C. NERIS ${ }^{1}$ e J. G. A. PACHECO FILHO ${ }^{1}$ \\ ${ }^{1}$ Universidade Federal de Pernambuco, Departamento de Engenharia Química \\ ${ }^{2}$ Universidade Federal de Pernambuco, Centro de Ciências Biológicas \\ E-mail para contato: shyrlane_veras@hotmail.com
}

\begin{abstract}
RESUMO - O tratamento através de reatores UASB é o sistema anaeróbio mais utilizado no tratamento de esgotos principalmente em regiões de clima quente, como o Brasil. Por isso, eles apresentam eficiência reduzida durante o inverno. $\mathrm{O}$ foco deste trabalho foi realizar um estudo comparativo entre a pirólise térmica rápida de duas amostras de lodo anaeróbio coletadas em períodos climáticos distintos. Os testes foram feitos em duplicata em um micropirolisador acoplado a um cromatógrafo GC-MS a $450^{\circ} \mathrm{C}, 600^{\circ} \mathrm{C}$ e $750^{\circ} \mathrm{C}$ para as amostras com granulometria em torno de 0,125 $\mathrm{mm}$. O desempenho dos experimentos foi avaliado quanto ao teor de hidrocarbonetos e compostos precursores de biocombustíveis obtidos. As amostras coletadas em período chuvoso e de estiagem forneceram maiores percentuais de compostos precursores de biocombustíveis a $750^{\circ} \mathrm{C}$, sendo este valor maior para o lodo coletado em período chuvoso $(42,6 \%)$, o que pode estar associado à baixa eficiência dos reatores UASB nestas condições climáticas.
\end{abstract}

\section{INTRODUÇÃO}

No reator UASB, o esgoto entra e é distribuído pela parte inferior do mesmo no qual flui pela zona de digestão, onde encontra-se o leito de lodo. Nesse ponto, ocorre a mistura entre o material orgânico contido no esgoto e o lodo presente no leito. Durante a mistura, os sólidos orgânicos são quebrados, biodegradados e digeridos anaerobicamente, resultando na produção de biogás e crescimento da biomassa bacteriana, que consequentemente contribui para o consumo do material orgânico presente no esgoto (AIYUK et al., 2006; CHONG et al., 2012). Esse tipo de tratamento é muito utilizado em regiões de clima quente, como as tropicais e subtropicais (CHONG et al., 2012), por isso apresenta menor eficiência de tratamento durante o inverno (KASSAB et al., 2010).

A fase sólida resultante do tratamento de efluentes geralmente é chamada de lodo, que é um material heterogêneo de composição complexa e com elevada quantidade de matéria orgânica. Nessa mistura heterogênea encontram-se microrganismos, material orgânico não-digerido como: papel, resíduos de vegetais, óleos vegetais e gorduras residuais, resíduos fecais, material inorgânico; além de um teor de umidade em torno de 60-85\% (SHAO et al., 2010; TYAGI; LO, 2013). 


\section{9 a 22 de outubro de 2014 \\ Florianópolis/SC}

O material orgânico não-digerido apresenta uma mistura complexa de moléculas derivadas de proteínas e peptídeos, lipídeos, polissacarídeos, macromoléculas vegetais com estruturas fenólicas (ex. lignina) ou alifáticas (ex. cutina e suberina) que normalmente estão associadas à micropoluentes orgânicos como os hidrocarbonetos aromáticos policíclicos ou dibenzofuranos. O lodo apresenta ainda em sua composição concentrações de nitrogênio, outros minerais e compostos químicos potencialmente tóxicos, nos quais estão inclusos alguns metais pesados como: chumbo $(\mathrm{Pb})$, cádmio $(\mathrm{Cd})$, cromo $(\mathrm{Cr})$, cobre $(\mathrm{Cu})$, mercúrio (Hg), entre outros (AGRAFIOTI et al., 2013; MANARA; ZABANIOTOU, 2012; TYAGI; LO, 2013). Porém, essa composição é relativa e depende muito do tipo de tratamento empregado além das características das fontes que o produziram.

Muitos dados reportados na literatura mostram o aumento da produção de lodo com o tempo, e, portanto, a necessidade em gerir adequadamente esses resíduos. A produção de lodo de esgoto no Brasil é estimada entre 150 a 220 mil toneladas de matéria seca por ano (VIEIRA et al., 2011). No Japão, esse valor aumentou de 1,63 milhões de toneladas em matéria seca em 1994 para 2,17 milhões de toneladas em 2004. Em 2006, na Coréia do Sul foram geradas por volta de 2,7 milhões de toneladas em base seca por ano, valor que passou a 4 milhões em 2013 (PARK et al., 2010; KWON et al., 2013). Em 2005, a produção de lodo pelos 12 estados membros da Europa (EU-12) foi estimada em torno de 1,1 milhões de toneladas em base seca por ano. Enquanto que os 15 outros membros (EU-15) foram responsáveis por mais 9,8 milhões de toneladas no mesmo ano, totalizando 10,9 milhões de toneladas em base seca por ano para todos os 27 estados membros (EU-27). Estima-se que esse valor exceda 13 milhões de toneladas em 2020 (KELESSIDIS; STASINAKIS, 2012).

Diante dessa situação, o foco principal para um gerenciamento ambientalmente adequado é priorizar a reutilização desses resíduos sólidos derivados do processo de tratamento de esgotos. Muitas são as alternativas em estudo e em operação para tentar resolver a questão da destinação do lodo resultante do tratamento de esgotos. Porém, nem todas essas alternativas permitem um uso adequado deste resíduo e/ou apresentam limitações. As estratégias mais comuns no Brasil, assim como na Europa, são: a disposição em aterros, práticas agrícolas e incineração (KELESSIDIS; STASINAKIS, 2012; MANARA; ZABANIOTOU, 2012). Embora, a destinação desses resíduos em aterros ainda seja a forma mais adotada pelas estações de tratamento no Brasil entre os demais métodos convencionais (VIEIRA et al., 2011).

Pensando nisso, como o lodo de esgoto é rico em matéria orgânica e apresenta poder calorífico semelhante ao do carvão, ele pode ser empregado como fonte de energia limpa, sendo considerado como uma biomassa combustível. Os processos térmicos como a pirólise utilizam a parte orgânica presente em sua composição e, como resultado, tem-se a geração de energia e cinzas. A pirólise promove a decomposição de materiais orgânicos na ausência total ou parcial de um agente oxidante. Nela geralmente é empregada uma temperatura que varia de $400^{\circ} \mathrm{C}$ até $750^{\circ} \mathrm{C}$ (temperatura de início da gaseificação), pois acima desta temperatura as taxas das reações para obtenção de bio-óleo são reduzidas. Basicamente, a pirólise fornece como produtos: bio-óleo, gases e resíduo sólido (carvão e cinzas) (MANARA; ZABANIOTOU, 2012; TYAGI; LO, 2013).

Então, sabendo que quanto maior a quantidade de matéria orgânica presente na biomassa, maiores as chances de obter melhores resultados na conversão da mesma e que em períodos chuvosos 


\section{9 a 22 de outubro de 2014 \\ Florianópolis/SC}

a eficiência dos reatores UASB é reduzida, o objetivo principal deste trabalho foi realizar um estudo comparativo em relação aos compostos pré-combustíveis e hidrocarbonetos obtidos através da pirólise térmica de amostras de lodo anaeróbio coletados em período chuvoso e de estiagem.

\section{METODOLOGIA}

As amostras de lodo foram coletadas no leito de secagem da ETE Mangueira, que utiliza o processo de tratamento anaeróbio através de reatores tipo UASB, em períodos climáticos distintos: chuvoso e de estiagem. Depois disso, as mesmas passaram por um processo manual para separação de resíduos grosseiros (embalagens plásticas, resíduos vegetais), moagem, peneiramento (em malha de 120 mesh) e homogeneização. Em seguida, as amostras foram separadas em pequenas quantidades e, por último, estocadas em frascos âmbar em temperatura ambiente.

\subsection{Determinação dos Percentuais de Umidade, Matéria Volátil e Compostos Inorgânicos}

Para a determinação do teor de umidade, tomou-se como base a ASTM D2216-98 (2005) na qual, uma determinada quantidade de lodo foi colocada em uma estufa a $110^{\circ} \mathrm{C}$ por $2 \mathrm{~h}$. Após atingir temperatura ambiente, foram realizadas pesagens até peso constante. A fim de obter uma indicação da quantidade de material orgânico presente nas amostras, foi feita uma estimativa da quantidade de voláteis nas amostras de lodo. Portanto, após o processo de determinação da umidade, o mesmo material seguiu para uma mufla a $550^{\circ} \mathrm{C}$ por $1 \mathrm{~h}$ em atmosfera de ar (AGRAFIOTI et. al, 2013). Para a determinação de metais e componentes inorgânicos, utilizaram-se análises com espectrômetro de raio$\mathrm{X}$ da Shimadzu, modelo EDX-700.

\subsection{Pirólises Térmicas das Amostras}

A pirólise rápida ocorreu em um micropirolisador CDS Pyroprobe 5200, acoplado a um cromatógrafo a gás com espectrômetro de massa Shimadzu GC/MS QP 2010 Plus. Aproximadamente $500 \mu \mathrm{g}$ de amostra foram colocadas em um tubo de quartzo entre uma pequena quantidade de lã de quartzo para fixá-la no tubo. Utilizou-se o hélio como gás de arraste ( $\left.1 \mathrm{~mL} \cdot \mathrm{min}^{-1}\right)$, coluna DB-5MS com espessura de $0,25 \mu \mathrm{m}, 30 \mathrm{~m}$ de comprimento e diâmetro de $0,25 \mathrm{~mm}$; a qual foi submetida a uma temperatura inicial de $40^{\circ} \mathrm{C}$ por 5 minutos, seguida de uma rampa de aquecimento sob uma taxa de $5^{\circ} \mathrm{C} \cdot \mathrm{min}^{-1}$ até atingir $300^{\circ} \mathrm{C}$, na qual permaneceu por 30 minutos. A fonte de íons foi mantida a $230^{\circ} \mathrm{C}$ e a interface a $250^{\circ} \mathrm{C}$, sendo a análise realizada no modo scan adquirindo massas no intervalo de 40 $533 \mathrm{~m} / \mathrm{z}$. As pirólises foram realizadas nas temperaturas de $450^{\circ} \mathrm{C}, 600^{\circ} \mathrm{C}$ e $750^{\circ} \mathrm{C}$ para as amostras, numa taxa de aquecimento teórica de $10^{\circ} \mathrm{C}_{\mathrm{ms}}{ }^{-1}$ e um tempo total de aquecimento de 40 segundos.

A interface do pirolisador foi aquecida a $110^{\circ} \mathrm{C}$ por 1 minuto, para secar a biomassa, aumentando-se para $325^{\circ} \mathrm{C}$ por 4 minutos. A linha de transferência e a válvula do pirolisador foram mantidas a $325^{\circ} \mathrm{C}$. Os produtos de reação foram identificados pela análise semi-quantitativa dos espectros de massa usando a biblioteca de compostos NIST. Foram considerados apenas os 70 picos principais, cada um com área percentual igual ou superior a $0,50 \%$. Os testes pirolíticos foram feitos em duplicata para tentar confirmar a reprodutibilidade do procedimento. Para cada produto 
identificado, foi utilizado o valor médio referente à área percentual dos picos, conforme realizado no trabalho de Lu et al. (2011).

\section{RESULTADOS E DISCUSSÃO}

\subsection{Caracterização das Amostras de Lodo Anaeróbio}

Os resultados referentes à determinação da umidade, quantidade de material em base seca, matéria volátil e fixa das amostras de lodo estão contidos na Tabela 1.

Tabela 1 - Propriedades Físicas do Lodo.

\begin{tabular}{lcc}
\hline Parâmetro & Período Chuvoso & Período de Estiagem \\
\hline Umidade (\%) & 6,46 & 4,26 \\
Material em base seca (\%) & 93,54 & 95,74 \\
Material Volátil (\%) & 35,05 & 42,59 \\
Material Fixo (\%) & 58,49 & 53,15 \\
\hline
\end{tabular}

$\mathrm{O}$ valor referente à quantidade de material orgânico foi um pouco maior para a coleta feita em período de estiagem, sendo a diferença em torno de 7,5\%. Isto pode ter acontecido, porque a diferença entre a quantidade de chuvas para elas tenham sido de aproximadamente 2 vezes $(410 \mathrm{~mm}$ e $220 \mathrm{~mm}$ de chuva acumulada mensal - INMET) sem influência significativa no processo de tratamento nos reatores UASB como no caso anterior. Espera-se que quanto maior o teor de material volátil no lodo, maior a chance de se obter compostos de interesse durante sua pirólise, principalmente hidrocarbonetos.

Embora, é importante reforçar que o processo de pirólise sofre influência de outros fatores como compostos inorgânicos, principalmente os metálicos ( $\mathrm{Ca}, \mathrm{K}$, Na, etc.). Normalmente, esses compostos são responsáveis pela aceleração das reações de desidratação e carbonização durante as reações primárias e secundárias. Como resultado, tem-se uma redução na quantidade líquida obtida (principalmente hidrocarbonetos) e um aumento na produção de gases e sólidos (AKHTAR; AMIN, 2012). Segundo Park et al. (2010) e Shao et al. (2010), elementos como Fe e Zn reduzem a decomposição da matéria orgânica e, conseqüentemente aumentam o tempo de pirólise. A Tabela 2 apresenta a quantidade compostos inorgânicos contidos nas amostras de lodo.

Tabela 2 - Percentual médio de componentes inorgânicos nas amostras de lodo.

\begin{tabular}{ccccccccccccc}
\hline \multirow{2}{*}{ Amostra } & \multicolumn{110}{c}{ Quantidade (\%) } \\
\cline { 2 - 12 } & $\mathrm{Fe}$ & $\mathrm{Si}$ & $\mathrm{Ca}$ & $\mathrm{S}$ & $\mathrm{Zn}$ & $\mathrm{K}$ & $\mathrm{Ti}$ & $\mathrm{Cu}$ & $\mathrm{Sr}$ & $\mathrm{Mn}$ & $\mathrm{P}$ & $\mathrm{Zr}$ \\
\hline $\begin{array}{c}\text { Período } \\
\text { Chuvoso }\end{array}$ & 26,6 & 43,1 & 12,4 & 5,2 & 1,3 & 2,8 & 1,5 & 0,3 & 0,3 & 0,2 & 5,6 & N.D. \\
$\begin{array}{c}\text { Período de } \\
\text { Estiagem }\end{array}$ & 29,1 & 31,4 & 17,9 & 9,7 & 1,7 & 2,6 & 1,6 & 0,4 & 0,3 & 0,4 & 4,4 & 0,4 \\
\hline N.D. = Não detectado. & & & & & & & & & & &
\end{tabular}


Comparando os valores contidos na Tabela 2, é possível observar que os dados obtidos para o lodo coletado em período de estiagem apresentaram maiores percentuais de elementos como Ca, $\mathrm{K}$, Fe e $\mathrm{Zn}$ em relação às amostras em período chuvoso, sugerindo que o desempenho do processo de pirólise nesta amostra pode ser reduzido devido à presença desses elementos.

\subsection{Análise dos Hidrocarbonetos e Compostos Pré-combustíveis}

Entre os produtos pirolíticos identificados, foram estudados com mais ênfase os grupos orgânicos precursores de combustíveis, sendo estes: hidrocarbonetos, alcoóis, ésteres e éteres. Essa análise foi realizada considerando a possibilidade de utilização da fração líquida, ou seja, bio-óleo como biocombustível. A Figura 1 mostra a distribuição dos hidrocarbonetos e compostos precursores de biocombustíveis obtidos para as duas amostras nas três temperaturas em estudo.

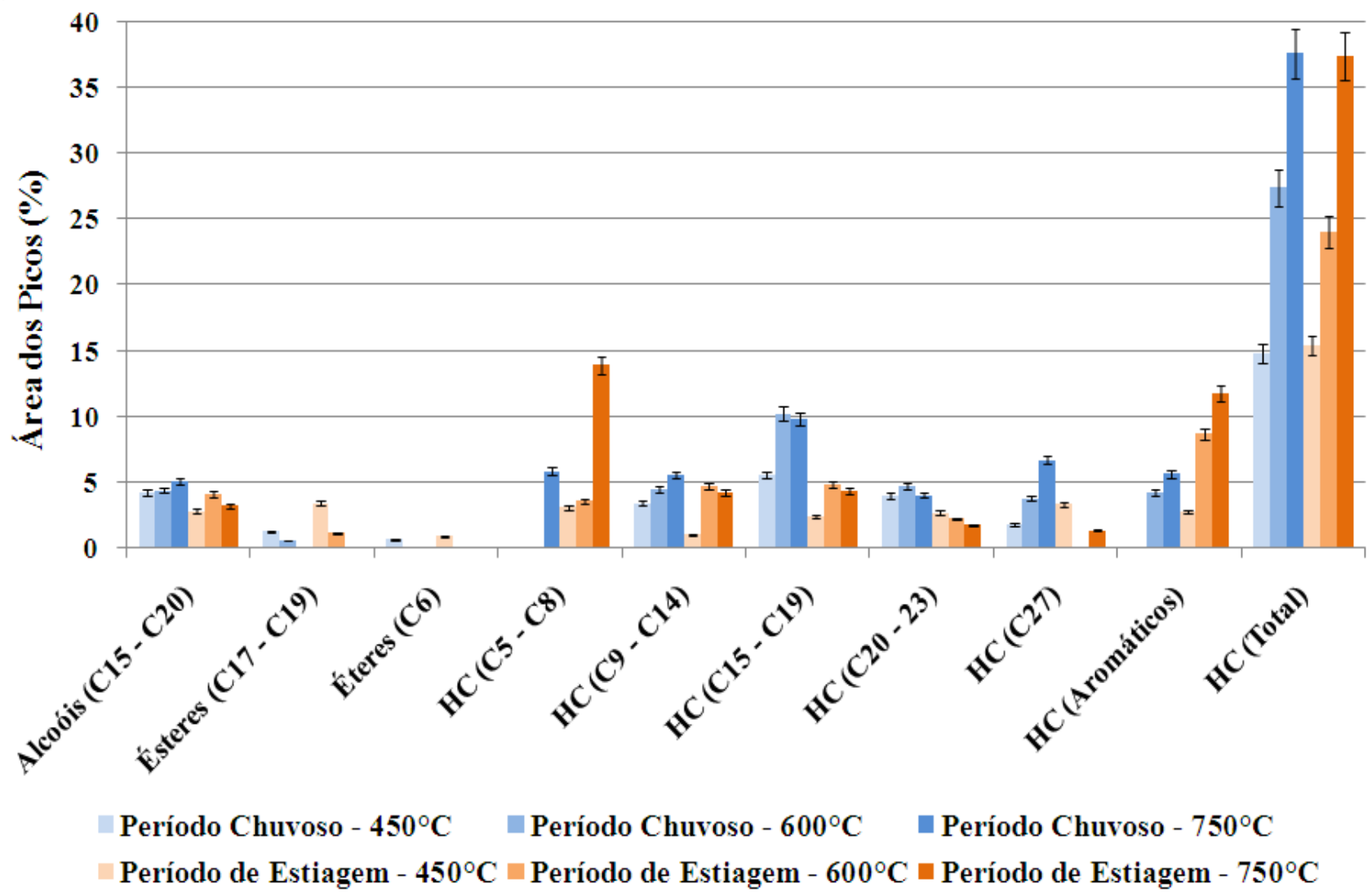

Figura 1 - Distribuição dos hidrocarbonetos e compostos pré-combustíveis obtidos através da pirólise rápida a $450^{\circ} \mathrm{C}, 600^{\circ} \mathrm{C}$ e $750^{\circ} \mathrm{C}$. Sendo ' $\mathrm{HC}$ ' $=$ Hidrocarbonetos.

A análise da Figura 1 permite observar a maior produção de alcoóis nas três temperaturas para a amostra de lodo coletado em período chuvoso. Além disso, foram obtidos maiores percentuais de hidrocarbonetos alifáticos, enquanto que a amostra do período de estiagem apresentou maiores 
percentuais em aromáticos, principalmente a $600^{\circ} \mathrm{C}$ e $750^{\circ} \mathrm{C}$. Nas duas amostras a produção de hidrocarbonetos aromáticos aumentou com a temperatura, conforme descrito por Sanchéz et al. (2009). Ésteres foram produzidos apenas a $450^{\circ} \mathrm{C}$ e $600^{\circ} \mathrm{C}$ e o único éter identificado foi o $1,4-$ dioxano apenas a $450^{\circ} \mathrm{C}$ para as duas amostras.

De modo geral, ambas apresentaram valores muito próximos para os hidrocarbonetos produzidos, em torno de $37 \%$ a $750^{\circ} \mathrm{C}$ e $15 \%$ a $450^{\circ} \mathrm{C}$. A amostra em período de estiagem mesmo apresentando maior percentual de matéria orgânica (43\%) em relação à amostra em período chuvoso (35\%), gerou uma menor quantidade de hidrocarbonetos e alcoóis, o que pode estar associado a variações na composição da biomassa e presença em maior quantidade de $\mathrm{Fe}, \mathrm{Zn}$ e $\mathrm{Ca}$, citados pela literatura como possíveis interferentes no processo pirolítico (AKHTAR; AMIN, 2012). De acordo com Kuan et al. (2013) e Park et al. (2010), a presença de Ca, por exemplo, reduz o rendimento em bio-óleo, porém aumenta a produção de $\mathrm{H}_{2}$, o que pode ter reduzido os percentuais de hidrocarbonetos alifáticos obtidos na amostra em período de estiagem.

Somando as áreas percentuais dos compostos para analisar o efeito da temperatura sobre a produção dos compostos de interesse, foi construído o gráfico apresentado na Figura 2. A partir dele é possível observar que os resultados foram proporcionais à temperatura, sendo maiores para a amostra em período chuvoso a $600^{\circ} \mathrm{C}$ e $750^{\circ} \mathrm{C}(32,3 \%$ e $42,6 \%$, respectivamente) em relação à amostra em período de estiagem $\left(29,2 \%\right.$ a $600^{\circ} \mathrm{C}$ e $40,5 \%$ a $\left.750^{\circ} \mathrm{C}\right)$, apresentando conformidade com a literatura. Segundo Akhtar e Amin (2012), a eficiência do processo de conversão da biomassa aumenta com a temperatura, pois em valores elevados, há um maior fornecimento de energia necessária para quebrar ligações entre os compostos presentes no material inicial.

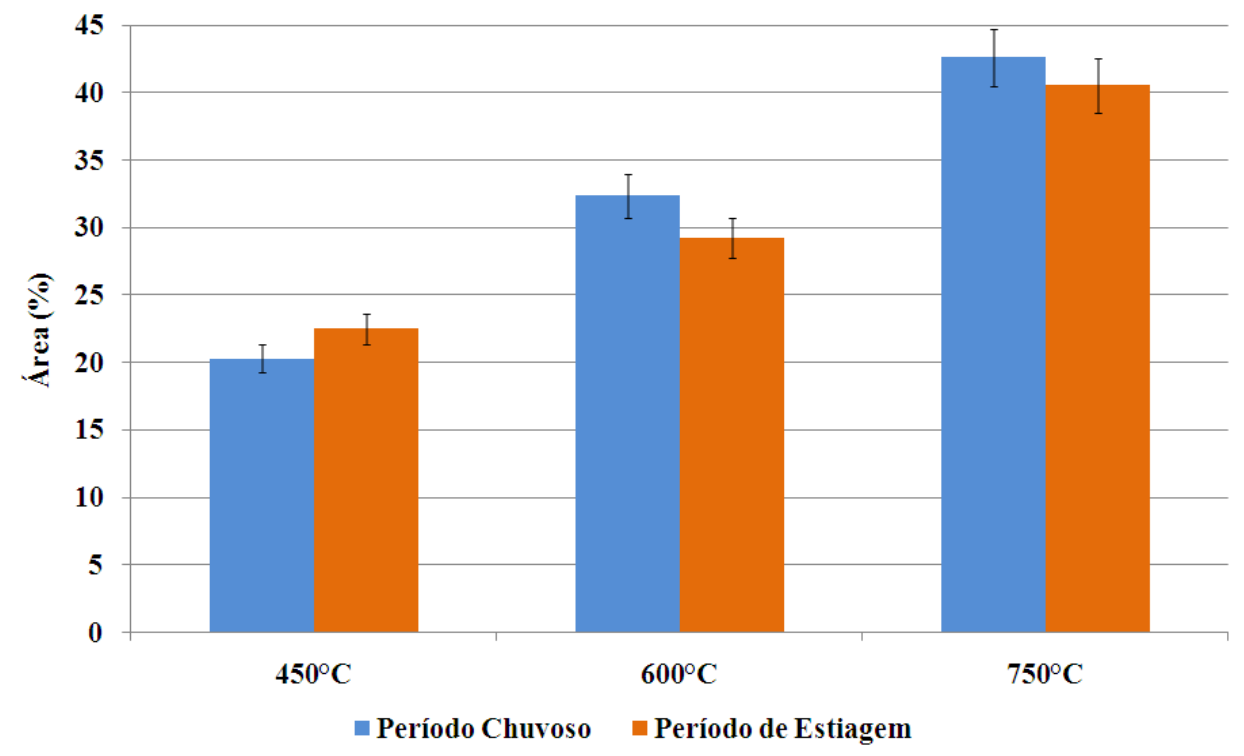

Figura 2 - Percentual de pré-combustíveis ( $\mathrm{HC}+$ alcoóis + ésteres + éteres) obtidos a partir da pirólise rápida das amostras a $450^{\circ} \mathrm{C}, 600^{\circ} \mathrm{C}$ e $750^{\circ} \mathrm{C}$.

Sendo: 'HC' = hidrocarbonetos. 


\section{CONCLUSÃO}

Os melhores resultados obtidos da pirólise rápida térmica vieram das análises do lodo coletado em período chuvoso: maiores percentuais para hidrocarbonetos alifáticos e alcoóis; e menor quantidade de hidrocarbonetos aromáticos. Considerando todos os compostos precursores de biocombustíveis obtidos pela pirólise do lodo, a amostra em período chuvoso também apresentou melhores resultados a $600^{\circ} \mathrm{C}$ e $750^{\circ} \mathrm{C}(32,3 \%$ e $42,6 \%$, respectivamente) em relação à amostra coletada em período de estiagem.

Esta última, mesmo apresentado maior percentual de matéria orgânica, forneceu menor rendimento em hidrocarbonetos. Embora, assim como na amostra em período chuvoso, foram obtidos melhores resultados a $750^{\circ} \mathrm{C}(40,5 \%$ para os compostos pré-combustíveis incluindo os hidrocarbonetos). Influências decorrentes da presença de metais e componentes inorgânicos podem ter contribuído para a diferença entre os resultados. No entanto, esses valores foram pequenos.

Com isto, é possível desenvolver estudos para aplicação do processo de pirólise com o objetivo de promover o aproveitamento deste tipo de resíduo, visto que normalmente ele segue diretamente para aterros sem nenhuma tentativa de reutilizá-los.

\section{REFERÊNCIAS}

AGRAFIOTI, E.; BOURAS, G.; KALDERIS, D.; DIAMADOPOULOS, E. Biochar production by sewage sludge pyrolysis. J. Anal. Appl. Pyrol., v. 101, p. 72-78, 2013.

AIYUK, S; FORREZ, I; LIEVEN, DE K.; VAN HAANDEL, A.; VERSTRAETE, W. Anaerobic and complementary treatment of domestic sewage in regions with hot climates - A review. Bioresource Technol., v. 97, p. 2225-2241, 2006.

AKHTAR, J.; AMIN, N. S. A review on operating parameters for optimum liquid oil yield in biomass pyrolysis. Renew. Sust. Energ. Rev., v. 16, p. 5101-5109, 2012.

ASTM D2216-98, Standard Test Method for Laboratory Determination of Water (Moisture) Content of Soil and Rock by Mass, ASTM, USA, 2005.

CHONG, S.; SEN, T. K.; KAYAALP, A.; ANG, H. M. The performance enhancements of upflow anaerobic sludge blanket (UASB) reactors for domestic sludge treatment - A State-of-the-art review. Water Res., v. 46, p. 3434-3470, 2012.

KASSAB, G.; HALALSHEH, M.; KLAPWIJK, A.; FAYYAD, M.; VAN LIER, J. B.. Sequential anaerobic-aerobic treatment for domestic wastewater - A review. Bioresource Technol., v. 101, p. 3299-3310, 2010.

KELESSIDIS, A.; STASINAKIS, A. S. Comparative study of the methods used for treatment and final disposal of sewage sludge in European countries. Waste Manage., v. 32, p. 1186-1195, 2012.

KUAN, W. H.; HUANG, Y. F.; CHANG, C. C.; LO, S. L. Catalytic pyrolysis of sugarcane bagasse by using microwave heating. Bioresource Technol., v. 146, p. 324-329, 2013. 
KWON, E. E.; YI, H.; KWON, H. H. Urban energy mining from sewage sludge. Chemosphere, v. 90, p. 1508-1513, 2013.

LU, Q.; YANG, X. C.; DONG, C. Q.; ZHANG, Z. F.; ZHANG, X. M.; ZHU, X. F. Influence of pyrolysis temperature and time on the cellulose fast pyrolysis products: Analytical Py-GC/MS study. J. Anal. Appl. Pyrol., v. 92, p. 430-438, 2011.

MANARA, P., ZABANIOTOU, A. Towards sewage sludge based biofuels via thermochemical conversion - A review. Renew. Sust. Energ. Rev., v. 16, p. 2566-2582, 2012.

PARK, H. J.; HEO, H. S.; PARK, Y. K.; YIM, J. H.; JEON, J. K.; PARK, J.; RYU, C.; KIM, S. S. Clean bio-oil production from fast pyrolysis of sewage sludge: Effects of reaction conditions and metal oxide catalysts. Bioresource Technol., v. 101, p. S83-S85, 2010.

SÁNCHEZ, M. E.; MENÉNDEZ, J. A.; DOMÍNGUEZ, A.; PÍS, J. J.; MARTÍNEZ, O.; CALVO, L. F; BERNARD, P. L. Effect of pyrolysis temperature on the composition of the oils obtained from sewage sludge. Biomass Bioenerg., v. 33, p. 933-940, 2009.

SHAO, J.; YAN, R.; CHEN, H.; YANG, H.; LEE, D. H. Catalytic effect of metal oxides on pyrolysis of sewage sludge. Fuel Process. Technol., v. 91, p. 1113-1118, 2010.

TYAGI, V. K.; LO, S. L. Sludge: A waste or renewable source of energy and resources recovery? Renew. Sust. Energ. Rev., v. 25, p. 708-728, 2013.

VIEIRA, G. E. G., PEDROZA, M. M., SOUSA, J. F. de, PEDROZA, C. M. O processo de pirólise como alternativa para o aproveitamento do potencial energético de lodo de esgoto - uma revisão. Revista Liberato, v. 12, n. 17, p. 81-95, 2011. 